\title{
Effects of Salt on Seed Germination and Seedling Growth of Three Portulaca Species
}

\author{
Orsolya BORSAI ${ }^{1,2}$, Mohamad AL HASSAN ${ }^{2}$, Monica BOSCAIU ${ }^{3}$, Oscar VICENTE ${ }^{2 *}$, Adriana SESTRAS ${ }^{1}$, \\ Radu SESTRAS ${ }^{1}$ \\ ${ }^{1}$ University of Agricultural Sciences and Veterinary Medicine Cluj-Napoca, Romania. \\ ${ }^{2}$ Institute of Plant Molecular and Cellular Biology (IBMCP, UPV-CSIC), and ${ }^{3}$ Mediterranean Agroforestal \\ Institute (IAM, UPV). Universitat Politècnica de València, Spain. \\ *)corresponding author, e-mail: ovicente@ibmcp.upv.es
}

BulletinUASVM Horticulture 72(2) / 2015

Print ISSN 1843-5254, Electronic ISSN 1843-5394

DOI:10.15835/buasvmcn-hort:11545

\begin{abstract}
We have determined the relative tolerance to osmotic/ionic stress of three Portulaca species ( $P$. halimoides, $P$. grandiflora and $P$. oleracea) at the seed germination and early seedling development stage. The three species are relatively resistant to stress, although at high concentrations $\mathrm{NaCl}$ strongly inhibited germination, whereas at the same osmotic potential PEG did not. Seedling growth was more clearly inhibited, in a concentration-dependent manner, with salt stress showing again a relatively stronger effect. Our data indicate that $P$. oleracea is the most salttolerant of the tested species and therefore the most promising candidate for 'saline agriculture', to be cultivated using low-quality, saline water for irrigation.
\end{abstract}

Keywords: Climate change, hypocotyl, Portulaca, radicle, salt tolerance.

\section{Introduction}

In the context of global climate change, with increased average temperatures, progressive salinisation of irrigated cropland and reduced availability of fresh water for irrigation, selection or development of novel crops with improved resistance to abiotic stress is becoming increasingly important for sustainable agriculture. This obviously applies to all our major food crops - environmental stress conditions, especially drought and soil salinity, are the main factors responsible for reduction of crop yields worldwide - but also to species cultivated at smaller scale for specific uses, such as ornamental, aromatic or medicinal plants. Among putative candidates, we can include several species of the genus Portulaca, which are highly appreciated for their nutritional value and traditional culinary and medicinal uses (e.g. common purslane, P. oleracea), or as ornamental plants, because their flower size and varied colours (e.g. P. grandiflora).

\section{Aims and objectives}

This work was carried out to evaluate the relative tolerance to osmotic and salt stress of three Portulaca species, at the germination and early seedling development stage - generally the most critical and stress-sensitive phase of the plant life cycle - as a first step to select the most appropriate to be cultivated under non-optimal conditions, in terms of water availability and quality.

\section{Materials and methods}

Seeds of $P$. halimoides, $P$. grandiflora and $P$. oleracea were germinated in Petri dishes (25 seeds per plate, 3 plates per treatment). Germination rates, radicle emergence, radicle, hypocotyl and cotyledonary leaf growth of seeds were determined after 14 days, at different osmotic potentials $(-0.25,-0.5,-1.0 \mathrm{MPa})$, generated by increasing concentrations of polyethylene 

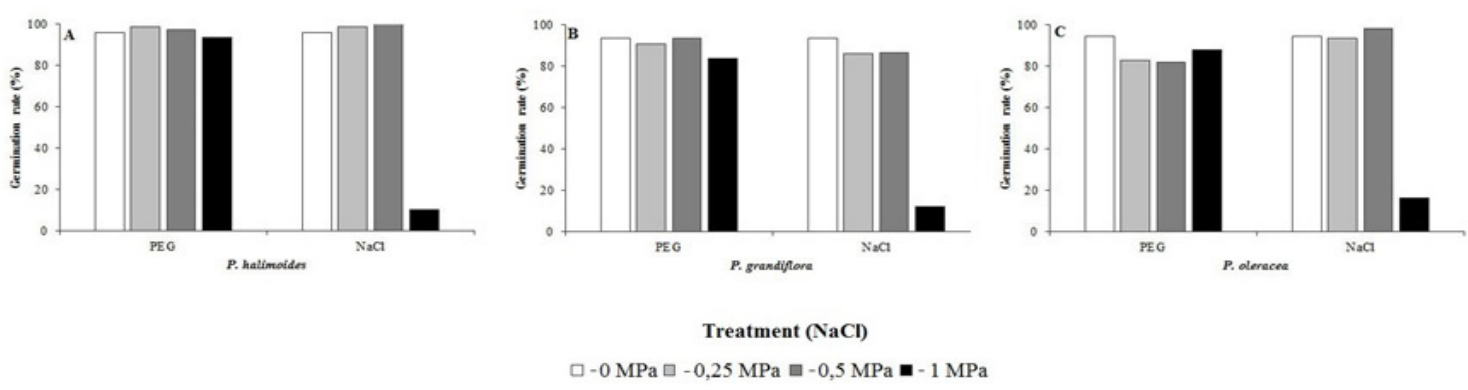

- $0 \mathrm{MPa} \square-0,25 \mathrm{MPa} \square-0,5 \mathrm{MPa}=-1 \mathrm{MPa}$

Fig. 1. Seed germination rates (\%) of the three selected Portulaca species at the indicated osmotic pressure, generated either by polyethylene glycol (PEG) or salt $(\mathrm{NaCl})$ treatments.

Tab. 1. Mean values of (A) relative radicle length (\%), and (B) relative hypocotyle length (\%) in germinating seeds of the three selected Portulaca species under the indicated osmotic pressure, generated by PEG or $\mathrm{NaCl}$ treatments. Values of control seeds germinated in water (0 MPa) were considered as $100 \%$, for each species and type of treatment.

\begin{tabular}{|c|c|c|c|c|c|c|c|c|c|}
\hline \multirow{2}{*}{\multicolumn{2}{|c|}{ (A) }} & \multicolumn{2}{|c|}{$0 \mathrm{MPa}$} & \multicolumn{2}{|c|}{$-0.25 \mathrm{MPa}$} & \multicolumn{2}{|c|}{$-0.5 \mathrm{MPa}$} & \multicolumn{2}{|c|}{$-1.0 \mathrm{MPa}$} \\
\hline & & PEG & $\mathrm{NaCl}$ & PEG & $\mathrm{NaCl}$ & PEG & $\mathrm{NaCl}$ & PEG & $\mathrm{NaCl}$ \\
\hline \multirow{3}{*}{$\begin{array}{l}\text { Relative radicle } \\
\text { length }(\%)\end{array}$} & P. halimoides & 100 & 100 & 114.20 & 82.58 & 85.54 & 76.79 & 87.71 & 0 \\
\hline & P. grandiflora & 100 & 100 & 77.23 & 39.14 & 61.15 & 23.47 & 68.36 & 0 \\
\hline & P. oleracea & 100 & 100 & 74.52 & 46.30 & 79.22 & 40.48 & 78.63 & 12.18 \\
\hline \multirow{2}{*}{\multicolumn{2}{|c|}{ (B) }} & \multicolumn{2}{|c|}{$0 \mathrm{MPa}$} & \multicolumn{2}{|c|}{$-0.25 \mathrm{MPa}$} & \multicolumn{2}{|c|}{$-0.5 \mathrm{MPa}$} & \multicolumn{2}{|c|}{$-1.0 \mathrm{MPa}$} \\
\hline & & PEG & $\mathrm{NaCl}$ & PEG & $\mathrm{NaCl}$ & PEG & $\mathrm{NaCl}$ & PEG & $\mathrm{NaCl}$ \\
\hline \multirow{3}{*}{$\begin{array}{l}\text { Relative hypoco- } \\
\text { tyle length (\%) }\end{array}$} & P. halimoides & 100 & 100 & 94.21 & 107.15 & 83.41 & 103.63 & 98.17 & 0 \\
\hline & P. grandiflora & 100 & 100 & 70.18 & 91.45 & 65.63 & 73.88 & 72.75 & 0 \\
\hline & P. oleracea & 100 & 100 & 104.61 & 116.44 & 85.25 & 111.83 & 94.71 & 95.57 \\
\hline
\end{tabular}

glycol (PEG) or NaCl. Distilled water was used to germinate control, non-stressed seeds.

\section{Results and Discussion}

Seed germination was relatively resistant to osmotic stress, with germination percentages over $80-90 \%$ for the three tested species, even in the presence of PEG or $\mathrm{NaCl}$ at $-0.5 \mathrm{MPa}$. Germination was not significantly affected by PEG even under more stressful conditions, at $-1.0 \mathrm{MPa}$, while it was strongly inhibited by salt at the same osmotic potential (Fig. 1), indicating that this process is relatively more sensitive to the toxicity of the salt than to its osmotic component. Seedling growth, assessed by measuring the relative radical and hypocotyle length, was more clearly inhibited in the presence of PEG and $\mathrm{NaCl}$, in a concentrationdependent manner (Table 1); here again, a relatively stronger effect was detected in the presence of salt than of PEG, at the same osmotic potentials. Moreover, significant differences were observed among the selected species, according to their relative degree of stress tolerance. Portulaca oleracea showed the lowest inhibition of seedling growth under salt stress conditions which, at the highest concentration tested, completely blocked seedling development in $P$. halimoides and $P$. grandiflora.

\section{Conclusion}

All three investigated Portulaca species are relatively resistant to osmotic stress, at least at the germination and early seedling development stage. Yet, their relative tolerance indicates that $P$. oleracea is the most promising candidate for 'saline agriculture', to be cultivated using saline or 'recycled' water (sewage, waste water from industry and agriculture, brackish water from saline aquifers, etc.) for irrigation. 